\title{
Retinal Arterial Branch Occlusion
}

National Cancer Institute

\section{Source}

National Cancer Institute. Retinal Arterial Branch Occlusion. NCI Thesaurus. Code C34436.

An occlusion of a branch of the retinal artery. 